\title{
Media ethics - principles and practices in Macedonian journalism
}

\section{Liljana Siljanovska}

Faculty of Languages, Cultures and Communications, South East European University, Tetovo, Macedonia

Email address:

1.siljanovska@seeu.edu.mk

To cite this article:

Liljana Siljanovska. Media Ethics - Principles and Practices in Macedonian Journalism. Social Sciences. Vol. 3, No. 3, 2014 , pp. 86-91. doi: $10.11648 /$ j.ss.20140303.14

\begin{abstract}
In the era of democratization of institutions in all spheres of social living and globalization on a large scale imposed by the rapid technical-technological development and modern communication, the issue of media ethics has become all the problematic and has been connected with the moral responsibility of journalists and the application of professional standards and criteria. In the countries with young democracies and transition of systems of social establishment among which is also the Republic of Macedonia, the behavior of the media and the rules of conduct of professionals were often prescribed and imposed by others: the government, the state, the ruling political parties or the media close to them. Respecting professional standards and criteria, especially in research journalism, is often reflected in media practice with certain misfortunes for journalists, administrative barriers, bans and court prosecutions. With the new national media laws, the fundamental human right to be appropriately informed is limited and repressed, and thus there is a maximal affirmation of a new, made-up and artificially construed right without any basis arising from the relevant international legal regulative. Journalistic ethics must firstly call upon the public which the media content is intended for, upon the goodness of those who are in dire need of the announcement and the content that can deeply influence their lives, in a good or a bad way. The ethic code of journalists and other media professionals is only the second name of the rules of conduct based on which the journalistic profession is founded. These rules make sense only if they arise from a broader social context that characterizes the acceptance of a certain system of universal values.
\end{abstract}

Keywords: Ethic Code, Moral Responsibility, Professional Standards, Research Journalism, Media Reality

\section{Introduction}

The ethic conduct of media is an issue problematized with the mere general setup of the theoretical discourse of ethics as a sublimate of the conscious and the responsibility in the manners, behaviors and conduct of people. The other maxim that defines the interaction of individuals, social groups and entities sets the relations of ethics in mass communication with focus on the separate influence and mutual causality of the source, the message and the receiver as fundamental elements of the communication process. Ethics, according to Aristotle, who is regarded as the founder of the theory on moral behavior, represents a specific form of human practice, i.e. a form of certain relation of man towards himself and towards others in all spheres of socio-political, economic and cultural life. Today, as an erosion of moral relations that rarely coincide with professional criteria and standards, ethics remains one of the most important issues of modern media. This is especially evident with the rise of deviant and asocial occurrences in young democracies, especially in postCommunist countries and the countries in transition of systems of convictions and beliefs. The moral principles in journalism are problematized as a theoretical perspective and practical application in countries of Southeast Balkans that also include the Republic of Macedonia. The analysis of media practice reactualizes the question asked by Max Webber in his work "Politics as a Vocation", and regards the amount of readiness in journalists and politicians in taking responsibility for the consequences of their actions. Actually, according to Webber, the debt to truth is considered as unconditionally necessary for absolute ethics that does not ask of the consequences. Politicians, according to Max Webber's analysis behave ethically responsible and act rationally - and accordingly. Despite that, this research intends to analyze and reactualize Webber's thesis on ethical awareness and rational values in media communication. In the process, there is an ethical 
dilemma on the specific meaning of the actual taking responsibility. This dilemma opens several other ethical questions of the type - what are the boundaries in which journalists can refuse responsibility regarding the consequences of their actions, to what extent are ethical principles such as duty and responsibility applied in terms of the source of information, the choice of topics and the organizational structure of media content and especially in terms of interest groups of the public for which the specific media content are intended for.

Research, methodologically speaking, has a qualitative approach and is based on interviews, analysis of media content, i.e. analysis of texts in printed media and analysis of programs of national televisions, as well as specific content on the social media. That corresponds to the questions on the application of media standards and criteria such as professionalization of media content and the application of moral principles of conduct of journalists in the execution of the journalistic profession. Actually, those were the basic parameters in research of ethics in the media space of the Republic of Macedonia with a tendency to generalize ethic and professional principles and rules in journalism through an analysis of cases of unethical examples and moral dilemmas of specific media products.

\section{Ethics in Mass Communication}

We cannot but communicate - is the note of the famous American psychologist and communicologist Paul Vaclavik. The need to establish interaction is found in the basis of communication science as a social process of exchange of information and their influence on the public. It arises from human necessity to be in contact with other people, to establish a feeling of mutual affiliation, loyalty and responsibility. The need for the existence of ethics in communication was first seen by German thinkers Karl Otto Apel and Jurgen Habermas (1981) according to whom there is a necessity for a universal harmonization and establishing an understanding amongst people in a society, and even on an international level. Apel and Habermas indicate that in order to have sound interpersonal relations there must be an effective communication directed towards creating:

"The full realization of the message(s), as well as the full awareness of other elements of behavior of those that communicate enables a successful communication that contributes to the building of sound human relations" [1].

The manner of establishing sound relations between people which is the ethical basis of the act of communication contains within the essential moral principles of the participants in communication. This means that the sender and the receiver of the message should have the will to express the message and to do so with paying an appropriate amount of attention to the person they are talking to, and should not disregard the non-verbal communication in the process. We start from the character and the meaning of the syntagma - the medium is a message - and above all of great meaning to the public, social character of an organized and publicly available message through the media. Thus, ethics in mass communication, or more specifically in journalism, can be defined as building sound social relations among all stakeholders in the communication process which in ideal theoretical and practical conditions represent high moral responsibilities of the source of the message, the medium and the public. The style which the journalist uses to communicate with the public, and which is expected to offer clarity in creating the content of the messages is of special importance for the ethics of the means for mass communication. This usually influences the quality of the relation which he has established or is yet to establish with the public. The journalist and the public are both sides of the communication process which immediately appear in media communication and who are equally affected by the quality of the process. That is why certain parameters need to be respected for it to be successful, and for both parties to be satisfied. It is highly important to create a feeling of equality and of unity. The creator of the media message and the receiver are connected by the public, social character of the content of the media product, and that is the awareness that the message is there for initialization, affirmation, popularization and for resolving a certain phenomenon, process or an event which arises from reality and has direct or indirect influences on the community. In the process, the elimination of the feeling of superiority and inferiority in the communicative interaction for a certain communicative reality represents an inseparable component in the moral behavior of the media as a socio-cultural entity and of the public in the broadest sense of the word. In the realization of mass communication processes and of grave importance is the maintaining of self-control and restraint from aggressiveness. Otherwise, analysis of media practice shows that in the organizing, the structure and the content of the communication message prevails coloring, negativism and one-sidedness. Often times, those are the main contexts in informing and the analytical process. The ethic issue in mass communication envisages supporting the mutual interest between the media and the public which if it is to be achieved in real, objective circumstances and with the application of professional standards and criteria, will result in authentic informing.

Journalists have more responsibilities towards: their profession, its legal framework and the public they are there to serve. Actually, their responsibilities coincide with the ones of the work-active people. Answering to their own profession journalists should be directed to a productive communication in the medium. This thesis which is confirmed in media practice implies quality in creating newspaper and program schemes, diversification of topics and versatility and objectiveness in the informative and research approach. That would decrease the pressure in the editorial policy through a return influence in the vertical communication which implies a constructive cooperation between journalists and editors in the interest of achieving 
a higher effect of the media product on the information market. The quality, more than anything, is important to the public especially to retain its attention and to form a focused public which will be prepared for civil participation as a driving force of democratic processes. Still, in no case can we disregard the fact that the medium primarily functions under legislation so that it may be in the service of the citizens. The journalist responsibilities are finalized as one big responsibility for the whole society.

Democratic ideology accepts free journalism although it is imperfect. This ideology is becoming more and more aware that the law is binding, and that moral was and will be a personal perception of the world which leads to dilemmas, but still democracy finds the courage and selfconfidence to choose knowledge and truth, as opposed to ignorance and propaganda. In his work "Politics as a Vocation", Max Weber asks how ready are journalists and politicians in taking responsibility for the consequences of their actions. Weber considers the debt to truth as unconditionally necessary for absolute ethics which does not ask of the consequences. Politicians, according to Max Weber's analysis, should be ethically responsible and act rationally - and accordingly. That means that politicians take responsibility for their actions and measure out the purpose, the assets and the possible side effects. As opposed to that, journalists orient themselves to be ethically aware and act to rationally. That means that they reject responsibility for their actions, although generally, the question "who exactly is taking responsibility?" remains unclear.

Research journalism intends to reveal the unknown, to take down the mask of the disguised or the concealed, and often times to even bring the journalist in life danger. An overview of some of the cases in the world are the murders of Anna Politkovskaya, Syed Saleem Shahzad or Ivo Pukanic which reaffirm this thesis. Due to that fact, that type of journalism is positioned on the border between good and evil. The public has a moral right to know what is going on behind their back, but should the journalist accept all in order to help it turn around and see?

The answer to that question from an ethical aspect is not easy, just as the answers to numerous other questions imposed by free journalism, because even journalism lead by man is as imperfect as much as him, and sometimes is not able to reach its potential.

\section{Ethical Dilemmas in Research Journalism}

In every applied area, ethical standards almost always face ethical dilemmas; hence open questions do not represent an exception in journalism. Due to this fact, very often there are disagreements with certain moral norms between citizens and journalists. The strive for moral balance is problematized with several still open questions. For example, is the graphic and visual representation of scenes of violence and death a more real way to convey an informative value of news? Should state secrets, which may upset the public, be disclosed by any means just to satisfy the public interest (whose concept is often changed if necessary)? Does taking pictures of public figures during their family vacation reveal something important about their social function or does it solely give us a sensational short-term feeling to be in their skin?

On certain occasions, even the source of information has the legitimate right to ask the journalist to stay anonymous or to not have his information disclosed. For example, if the scientist that announces to the journalist information regarding an important experiment that he is is currently working on, due to the goals of the research, the change of facts, can ask that his statement should not be published in the media until the experiment is scientifically completed. An ethically correct journalist without a doubt should wait to inform the public regarding this issue. Journalistic report is a two-edged sword. Such an example is the case with the reporter from the New York Times, Judith Miller who was even placed behind bars for respecting the will of her sources (a secret agent of the US intelligence services) to remain anonymous.

The presence of ethics in the journalistic sphere cannot and should not place a strict and precise boundary between the professional and the moral dimension, but through their "melting" into one dimension, should try to offer a pathway to reasonable and righteous decisions in regard to a certain dilemma.

A journalist's parameter for professionalism is his effort to get to the truth, but the only problem is that there is not absolute truth. The journalist must follow the leads of a certain source that can be incorrect, and the journalist might not be fully aware of it. Even his efforts for at least two sources of the same information in the interest of balancing the situation may essentially mean an incomplete and nonobjective communication message due to the insufficient choice of media sources in terms of competency and the degree of their professional information on a certain segment. Thus, a completely sufficient moral accomplishment for him is not to deliberately publish the information that he is fully aware is a lie.

In the selection of sources of information it is of grave importance that the journalist consult several and independent one-from-another sources regarding the information of same phenomenon, because that is the only way, ethically, to initiate different opinions to the public that follows his work through the media. -Pluralism is important for a healthy development of a society, because if everybody thinks the same, then no one is actually doing much thinking. (A statement of the famous American political commentator, reporter and writer, Walter Lippman)

Regarding that, journalists should encourage a healthy social debate upon vital issues about the community, because with that they contribute to the creation of an environment where interpersonal relations are developing 
in a positive direction. At the same time, journalist should maintain a level of debate in order to discourage the spreading of lies and pejorative attacks on individuals, because that is opposite to what is imposed by ethics. The right to free speech belongs to everyone as a mandatory human right, and even if there is a mutual radicalization in the expressed opinions.

The individual, who due to certain reasons (productive or destructive) becomes the focus of the medium itself is equally important as the entire public. That is why the journalist must treat the individual as any other human being, with respect and cultural sensibility.

The activist for homosexual rights that decides to publicly protest and is, in the process, covered by the media should not be at any point belittled by the journalist if they differ in opinions, nor should the journalist treat him with offensive words. The activist is not just a follower of certain claims that are approved, i.e. discarded. He can be somebody's father, son, valuable worker, a great expert in a field, and thus, a worthy citizen of the country who deserves a proper treatment.

\section{Ethics of the Media Message in the Macedonian Cases of Media Practices}

The news, regardless of the topic that is being reported, often causes certain feelings with the public. The moments where the reader remains neutral and unmoved while reading information in a daily newspaper are rare, if not non-existent. Given the professional criteria on organizing the news as a media product, it should inform through facts and indicate sources that will explain the reasons for organizing the message. However, media practice in Macedonia often shows unilateral tendentiousness coloring and an expressed negativism in short informative content, i.e. news. This is more noticeable in electronic news - on the radio and television through the general previews of the prime time news, separate announcements and the sign offs in news where separate anchormen allow themselves comments and impose views in forming the public opinion on a specific event or phenomenon. The analysis of media cases shows that in the program of Macedonian televisions the informative space in the media of the opposition is usually directed in creating a negative image of the government and discrediting certain public figures, that there is no separation of the information from the commentary, i.e. reports from events are being commented, have a tendency to be selectively analyzed or through insertions of epithets and inserted sentences or word of the type - still, however, if, although, and despite, channelize the attention of the public for certain political and party interests or for certain financial goals. In the printed media this is expressed through the unequal space for source of information, and mostly through titles that instead of informing reach conclusions and form opinions in the written informative media genres. There is no doubt that the journalist has a duty to present information of public interest, because they affect the public. That is why it is necessary not to spin the fact from news, and the columns and commentaries should be specially denoted.

However, in terms of the background of the essence of the message there is yet an inconsistency, especially starting from the right to express the personal views of the medium. Moral dilemmas are open especially in coverages, documentaries and life stories of the poor, the downtrodden, the social cases and especially of the minor offenders and convicts for certain asocial phenomena. For example, the serial of documentaries on the odyssey of the homeless, sick children, and white slavery shown on certain Macedonian national televisions have a humane, social interest to capture the image of a certain segment of the community by finding solutions by the authorities for overcoming certain social realities. However, for the source of information transferred by image and sound they represent a reenactment of unpleasant feelings, memories and negative reactions that touch upon the ethic issue whether reporting is not an additional torture or revisit of unpleasant scenes. Or, the poor, the sick and the downtrodden whose fates have been discussed or have been written about in a certain media story, often times their photographs and statements, without their knowledge are used in political videos of parties to show the current social situation in Macedonia which represents abuse, an attack on one's dignity and integrity.

Numerous ethic situations occur daily in research journalism. Journalists fall under the influence of power and money, and working for influential people encourages their desire for power and influence. They try to get to that through different situations such as addictions in a celebrity, a company, a political party, by covering up stories, attacking one's identity, accepting bribes etc.

Journalistic professionalism means that the journalist should report accurate information, to do research, to look for answers, to serve the public. However, many disrupt their professionalism from the moment they construe stories according to their own opinions and views regardless whether they are competent to speak on the subject. Labeling on an ethnic, gender, political and religious basis, reduction and selection in the media stories, discrediting the government and the political elite under the vail of independence of journalists are the most common generalizations of the results of the analysis of the research issue - media ethics - principles and practice in Macedonian journalism. And instead of three sources of the story - the argument for which it is published, the second source - the argument against or the counterargument, and the third source - the expert public, the ordered texts with a marketing character which benefit certain political and business groups, disrupt the professionalism of the journalistic profession and actualize the issue of ethics such as rational behavior and the application of awareness for reprofessionalization of an already existing professionalism, 
i.e. the application of objectivity, balance, accuracy and verification of the sources.

Here are some of the reactions of journalists and guild associations in Macedonia in terms of the moral behavior of their colleagues in exercising the journalistic profession:

-The Court of Honor of the Journalist Association of Macedonia condemned the editor of the portal Maktel(quote) Is there anything humane in wishing for someone's death? Nothing ethical and professional can be found in the text of Sashe Ivanovski entitled "Igor Dzambazov - Trajche The Woodworker That Never Grew Up And Became A Man, But Turned Into The Strongest Ad For Alcohol And A Failed Life". (Published in Dnevnik, on 16 October, 2013)

-The past several years the media are filled with sensational stories on the topic "pedophilia". The most recent example is the cover of a daily newspaper with sensational title "A Pedophile Shot in Skopje in 1987!", and a subtitle "In Macedonia in the 80s there were several death sentences, one of which was for pedophilia executed by the order of the county court". The article calls upon another article published in another daily newspaper on February 4, 1987, "Criminal Sentenced to Death".

- An Albanian will advise Gruevski - which language will he be speaking (Utrinski vesnik, 25 February, 2013). An ethnic coloring in the title has the tendency to minimize the role and importance of the function of the chosen advisor on an ethnic basis.

\section{Self-Regulation and Ethic Codes}

Self-regulation is proposed as an appropriate and ethically justified alternative, through which the journalist is freed from the pressure of state influence, and still retains and follows the moral behavior towards the public.

Self-regulation can be realized through several instances, for example, by directly appointing attorneys (partially employed persons in the medium) that directly follow the opinion of their public by reading and responding to their letters, calls to the editorial staff. The Councils of Journalists maybe the most transparent manner of selfregulation practiced in, for example, the USA. Those are organizations that can function as civil initiatives, nonprofit or multilateral organizations such as UNESCO, but are always independent from the government. Their competencies are similar to the attorney's, and can be applicable on a local, national and regional level, suggesting directions on ethic basis.

However, ethic codes that arise from the medium are the most specific form of journalistic self-regulation, to which the medium and the journalist of that medium are morally bound. Such codes propose voluntary directions that contain ethic codes of duties and responsibilities of the journalist. There are a great number of ethic codes that the media decide to practice, which generally through different formulations are based on the unique moral principles. The best example for such an ethic code is that of "The Society of Professional Journalists" which through its fundamental principles, in an essential manner represents those journalistic duties that affirm the ethic presence in journalism [3].

- The journalist should look for the truth and research on it.

- The potential damage should be brought to a minimum - all subjects that (in)directly are connected with the journalist should be treated as human beings.

- The journalist should act independently, because the interest of the public is to know the truth and that is the only thing that he should be dedicated to;

- Accountability towards the public is mandatory.

\section{Conclusion}

Mass media in conditions of creating the awareness of an informed citizen with a creative and critical thought increase the social position by redefining their polyvalent role in society through the syntagma of professional and ethic norms of journalistic behavior.

By focusing on research stories on important questions of the lives of the citizens the media create a mechanism of self-regulation in research stories on the one hand, and on the other represent a corrective of the government by encouraging a parallel participation of citizens in social processes. Journalistic reporting immediately influences the cognitive dimension of citizens, giving them information that help them reach decisions on which school is better for their child, all the way up to who they should (not) vote for on the next elections.

"Journalism is a guardian that never sleeps and protects the freedom of the people," noted Winston Churchill. Freedom is the starting point for the existence of journalism. All of the important international institutions, organizations, conventions such a the United Nations, the European Commission, the Universal Declaration for Human Rights agree that the freedom of the media and journalistic expression have a need to be balanced by laws. It has come to this due to the explicit or implicit existence of opposing interests between media reporting and state government. Due to these different interests, as well as from the need to nurture collective relations in the civilized world, the need for security and equal protection of both sides is inevitable. Opposing interests are the biggest challenge of free society that open a great deal of dilemmas in the declaration of professional journalistic work, thus the need for ethic standards.

The freedom of journalism is embedded in a legal framework that is synchronized with journalistic responsibility - the next essence of this social activity.

\section{References}

[1] (Temkov, K., Ethics for Second Year of the Reformed High School Education, Skopje: Prosvetno delo, 2005:47) 
[2] (A report of the Judith Miller case by CNN; 10.28.2005 http://articles.cnn.com/2005-09-

30/politics/cia.leak 1 joseph-tate-cia-leak-judithmiller?_s=PM:POLITICS).
[3] (SPJ Code of Ethics, The Society of Professional Journalists, SPJ National Convention, 1996). 